Current Issues of Education and Science, 2021

DOI: $\underline{\text { https://doi.org/10.26697/9786177089147.2021.02 }}$

\title{
The Role of Sports Activities in Students' Academic Achievements in Secondary Education
}

\author{
Iris MANCI ${ }^{1}$ \\ ${ }^{1}$ Alexander Moisiu University, Albania \\ Corresponding Author Details \\ Iris MANCI, iris.manci@ hotmail.com
}

Received: 12.10.2021; Accepted: 09.11.2021; Published: 17.12.2021

\section{Brief Summary}

Background: Physical education is an integral part of the educational process, without which the child's education would be incomplete, but at the same time an area which differs from other curricular areas, as its primary focus is on the body, physical experiences and human health.

The aim of the study: To define the role of sports activities in students' academic achievements in secondary education.

Methods: The research is based on qualitative scientific research, which helps us to achieve new results and knowledge. Based on the direct observation at school to see the impact of sports activity on students' academic achievement 100 secondary school students in several different schools in the city of Durres were interviewed.

Results: The results of this study highlight the importance of the role of sports activities in school settings that take place at different times. Students have expressed that they get high results in lessons in subjects such as mathematics, reading, etc.; in improving academic performance; in concentration, beneficial effects on the processes of attention, memory, improving executive function and brain activation, and their behavior in the classroom.

Conclusions: Physical education plays an important role in promoting healthy behaviors. Students in physical education, compared to 
those who are not in physical education, are more physically active, eat more fruit, and watch less television. From a social point of view, students say that they cooperate more with their peers.

\section{Keywords:}

sport, education, student, teacher, academic achievements.

\section{Background:}

Research shows that physical activity - whether it's team sports, bike riding, swimming at the beach or playground games - has positive effects on the brain and on school performance. Physical activity has an impact on cognitive skills such as concentration and attention, and it also enhances classroom attitudes and behaviors, all of which are important components of improved academic performance. Children participating in the study were given electroencephalograms (EEGs) to measure brain waves and how fast the brain responds to certain stimuli. There is an extensive literature concerning the effect of single bouts of physical activity on cognitive function in young people and some studies examining the longitudinal (or chronic) impact of undertaking extra physical activity over or example a few months on cognitive function.

It is important to include such information in this review as each physical education lesson or sport activity represents a bout of physical activity which might impact on learning on that day and indeed over a period of time. Cognitive function is often examined using computer tests and may include tests of memory, attention, perceptual skills and occasionally in longitudinal, studies IQ tests. Researchers found that the brain synapses of physically fit children fired faster and stronger, and as a result those children had better language skills. The more physically fit children were not only better at reading, but they were also better at reading passages with several grammatical errors.

The researchers looked at the brainwave patterns that deal with language and the ability to spot errors in grammar. The fit children had strong results with both brain wave groups and a better understanding of nonsensical or error-filled sentences. Another study also found positive associations between physical activity, fitness, cognitive function and academic achievement. The evidence indicated that physical activity has a relationship to parts of the brain that support complex cognitive processes during laboratory tasks. It also showed that physical activity is important for growth, development and general health.

The aim of the study. To define the role of sports activities in students' academic achievements in secondary education. 


\section{Methods:}

This research is based on qualitative scientific research, which helps us to achieve new results and knowledge. Based on the direct observation that made at school to see the impact of sports activity on students' academic achievement and 100 secondary school students in several different schools in the city of Durres were interviewed. These methods adapted to the aims of this study. Various literature was also analyzed to create a theoretical framework regarding the importance and impact that sport has on its apparently high academic student activities.

\section{Results:}

Physical and sports education, like any other discipline, affects shaping the personality of young people, enabling them to actively participate in social activities in enriching and deepening general and specific knowledge, which enable them to become responsible, open, capable citizens to integrate in a democratic society. Through physical, sports and artistic activities we form cultured, independent citizens, who know how to control their physical development during schooling and throughout life, to regulate social relations, to be active actors and critics of what happens to them and about tire.

Through physical and sports activities students of this age gain new technical and tactical knowledge from a certain branch of sports, adapt in new specific situations and gain new experiences, making efforts to find better choices in specific physical activity situations. The knowledge gained through physical activities enables students to know how to behave within the group, to know and use the rules of behavior, but also to design those rules that they will respect. They will also express their organizational skills, as they will organize competitions, will judge them, while experiencing many emotions as participants in those competitions.

A review of the literature revealed that the key health benefits of sport on young people could be grouped into the physical and mental categories of health. Although the enhanced emotional wellbeing of young athletes was mentioned, there were no specific benefits noted in relation to this. Moreover, there does not appear to be literature concerning the link between sport and spiritual health. Further research regarding the social benefits of sports participation however did indicate that there is existing literature available which examines the relationship between the two variables. This centers around the facilitation of social inclusion (Collins, 2003). That is, sport is seen to provide an opportunity for individuals from different backgrounds to meet, communicate and thus develop social networks and unite communities (Bailey, 2004). 
Children's engagement in sports is known to contribute to outcomes to create a way of life for children, that children are for physical, social and cognitive abilities (Choi et al., 2014). More broadly, involved in physical activity is also known to contribute to a range of positive outcomes, importance; physical and mental health, social well-being, cognitive and academic performance (Bailey et al., 2013). For young people to have such results, it is accepted that physical education (PE) in schools is an ideal tool to promote physical activity because of its availability to all young people. While teachers also have the opportunity to integrate this process into education in general (Telford et al., 2012).

Self-determination theory suggests that the affective field (psychological need) is critical to students' growth, development, and wellbeing; in sports activity, students have the opportunity to experience autonomy and competence, components of learning that lead to increased self-efficacy and successful self-management (Shen et al., 2009). Highintensity sports activity significantly improves adolescents' non-verbal and non-verbal ability, abstract reasoning, spatial ability, and numerical ability (Ardoy et al., 2013). Sports activity increases the ability to manage time in completing classroom tasks (Fisher et al., 2011; Mahar et al., 2006). Academic performance improves when more time is spent on sports activities (Sallis et al., 1999; Shephard, 1997). Daily sports activity can enhance various cognitive abilities, such as fluid intelligence and perceptual speed of children in grade 2 through 8 (Reed et al., 2013).

There is a wealth of literature to suggest that physical activity is significantly related to increased self-esteem and speculated "knock-on" effects of this are benefits in all aspects of school life, including improved classroom behavior and academic performance (Shephard, 1996). The influence of physical activity on self-esteem may be influenced by the activity mode undertaken, although positive cognitive behavioral modifications have been observed across aerobics, strength, dance, and flexibility activities (Strong et al., 2005). One recent well-controlled study has shown improvements in self-esteem following running activities in girls (DeBate et al., 2009).

It is of particular interest that increased self-esteem is often thought to provide the impetus to participate in physical activity and sport, and that low self-esteem is often a key barrier preventing participation. Thus, development and inclusion orientated interventions shown to increase selfesteem could be the trigger for increasing youth engagement in physical activity. Conducting such interventions in schools means that little effort is required for pupils to become involved (compared to specialist, out of school clubs), and could provide the catalyst for the cyclical trend of 
increased self-esteem leading to increased participation. Further longitudinal research is required to firmly establish this concept however, as cross-sectional studies which observe high-exercise groups with lower levels of depression and high self-esteem cannot ascertain the direction of such a relationship (Field et al., 2001; Tremblay et al., 2000).

Behavior is a form of communication which is often the only way they know to communicate a desire or need. Determining the reason or cause of the behavior is a key factor in understanding the behavior and what it is trying to communicate. Children with disabilities need to learn skills that will help them reduce stress, irritability, improve communication skills, and develop new behaviors. During sports activity four psychological needs are also met that promote motivation, as Glasser says.

These four needs are: the need for belonging; the need for power; the need for freedom and independence as well as the need for pleasure.

Thus, allowing these children to work in groups, in pairs, or individually during this activity, practically meets their need. They feel free there, they feel emotionally fulfilled and motivated. They also fulfill a need which is freedom of action, there they discharge a lot of energy.

Taras (2005) reviewed literature investigating the association between physical activity and academic outcomes among school-aged children. It was recognized that physical activity is well associated with improved overall health and that among school-aged children it can help develop social skills, improve mental health, and reduce risk-taking behaviors. It was concluded that there may be some short-term benefits of physical activity, such as concentration. The long-term improvement on academic performance is a result of more vigorous physical activity but further research is needed in this area. Trudeau and Shephard (2008) reviewed the literature on the relationship between PE, school physical activity and school sports on academic performance. They concluded that physical activity can be added to the school curriculum by taking time from other subjects without the risk of hindering student's academic achievement. Further conclusions were made stating the literature strongly suggests that academic achievement, physical fitness and health of children will not be improved by limiting the time allocated to PE instruction, school physical activity and sports programmes. It was also reported that crosssectional studies generally indicate a positive association between physical activity and academic achievement.

The results of this study highlight the importance of the role of sports activities in school settings that take place at different times. Students have expressed that they get high results in lessons in subjects such as mathematics, reading, etc.; in improving academic performance; in 
concentration, beneficial effects on the processes of attention, memory, improving executive function and brain activation, and their behavior in the classroom. Physical education plays an important role in promoting healthy behaviors. Students in physical education, compared to those who are not in physical education, are more physically active, eat more fruit, and watch less television (Tassatano et al., 2010). From a social point of view, students say that they cooperate more with their peers. Many studies point out that sports activity further promotes a child's personality; creates solidarity and socialization; teaches children to set goals and how to deal with problems.

A review by Choi et al. (2014) addresses this gap in the literature, recognizing the wide range of positive outcomes that exposure to sports competition can have on children early in life (behavioral, physical and psychosocial). Most notably, through competition children are provided with excellent opportunities to build their skills, develop their social adjustment; integration and emotional growth. Competition is also thought to contribute to children's ability to work with others in the achievement of shared goals. When it comes to long-term success, competition helps children be better prepared for the challenges they will face in the future, whilst helping them to learn effective emotional and psychological skills and strategies to deal with winning and losing, as well as success and failure (Choi et al., 2014).

The results of this study reiterate the importance and necessity of conducting sports activities in the school, leading to some recommendations for physical education teachers as a key player in this process of student education.

\section{Conclusions:}

Sports activity has an impact on the student: sports activity is related to the measures of the executive function of the brain; sports activity results in the development of higher processes of storing information in memory; sports activity reduces problematic behaviors in the classroom; children who engage in sports activities receive higher grades in school; sports activity has beneficial effects on attention processes in students in the classroom; sports activity affects concentration, memory and classroom behavior; adolescent sports activity in leisure time is associated with greater cognitive performance; high-intensity sports activity significantly improves adolescents' non-verbal and non-verbal ability, abstract reasoning, spatial ability, and numerical ability; high school students have higher grade point average during semesters when dealing with sports compared to those who do not engage in sports; sports activity increases the possibility of time management in carrying out classroom tasks; daily sports activity can 
enhance various cognitive abilities, such as fluid intelligence and children's perceptual speed.

\section{Conflicts of interests:}

The author declares that there is no conflict of interests.

\section{Source of support:}

This research did not receive any outside funding or support.

\section{References}

Ardoy, D. N., $\quad$ Artero, E. G., $\quad$ Ruiz, J. R., Labayen, I., Sjöström, M., Castillo, M. J., \& Ortega, F. B. (2013). Effects on adolescents' lipid profile of a fitness-enhancing intervention in the school setting; the EDUFIT study. Nutricion hospitalaria, 28(1), 119-126. https://doi.org/10.3305/nh.2013.28.1.6146

Bailey, R. P. (2004). Evaluating the relationship between physical education, sport and social inclusion. Educational Review, 56(3), 7190. https://doi.org/10.1080/0013191042000274196

Bailey, R., Hillman, C., Arent, S., \& Petitpas, A. (2013). Physical activity: An underestimated investment in human capital? Journal of Physical Activity \& Health, 10(3), 289-308. https://doi.org/10.1123/jpah.10.3.289

Choi, H. S., Johnson, B., \& Kim, Y. K. (2014). Children's development through sports competition: derivative, adjustive, generative, and maladaptive approaches. Quest, 66(2), 191-202. https://doi.org/10.1080/00336297.2013.861757

Collins, M. (2003). Constraints on and benefits of playing sport. In M. Collins \& T. Kay (Eds.), Sport and Social Exclusion (pp. 24-33). Routledge. https://doi.org/10.4324/9780203167267

DeBate, R. D., Gabriel, K. P., Zwald, M., Huberty, J., \& Zhang, Y. (2009). Changes in psychosocial factors and physical activity frequency among third- to eighthgrade girls who participated in a developmentally focused youth sport program: a preliminary study. Journal of School Health, 79(10), 474-484. https://doi.org/10.1111/j.1746-1561.2009.00437.x

Field, T., Diego, M., \& Sanders, C. E. (2001). Exercise is positively related to adolescents' relationships and academics. Adolescence, 36(141), 105-110. https://pubmed.ncbi.nlm.nih.gov/11407627/ 
Fisher, A., Boyle, J., Paton, J., Tomporowski, P., Watson, C., McColl, J. H., \& Reilly, J. J. (2011). Effects of a physical education intervention on cognitive function in young children: randomized controlled pilot study. BMC Pediatrics, 11, 97. https://doi.org/10.1186/1471-243111-97

Mahar, M. T., Murphy, S. K., Rowe, D. A., Golden, J., Shields, A. T., \& Raedeke, T. D. (2006). Effects of a classroom-based program on physical activity and on-task behavior. Medicine and Science in Sports and Exercise, 38(12), 2086-2094. https://doi.org/10.1249/01.mss.0000235359.16685.a3

Reed, J. A., Maslow, A. L., Long, S., \& Hughey, M. (2013). Examining the impact of 45 minutes of daily physical education on cognitive ability, fitness performance, and body composition of African American youth. Journal of Physical Activity \& Health, 10(2), 185197. https://doi.org/10.1123/jpah.10.2.185

Sallis, J. F., McKenzie, T. L., Kolody, B., Lewis, M., Marshall, S., \& Rosengard, P. (1999). Effects of health-related physical education on academic achievement: Project SPARK. Research Quarterly for Exercise and Sport, 70(2), 127-134. https://doi.org/10.1080/02701367.1999.10608030

Shephard, R. J. (1997). Aging, physical activity, and health. Human Kinetics Publisher.

Shephard, R. J. (1996). Habitual physical activity and academic performance. Nutrition Reviews, 54(4), S32-S36. https://doi.org/10.1111/j.1753-4887.1996.tb03896.x

Strong, W. B., $\quad$ Malina, R. M., $\quad$ Blimkie, C. J., $\quad$ Daniels, S. R., Dishman, R. K., Gutin, B., $\quad$ Hergenroeder, A. C., $\quad$ Must, A., Nixon, P. A., Pivarnik, J. M., Rowland, T., Trost, S. \& Trudeau, F. (2005). Evidence based physical activity for school-age youth. The Journal of Pediatrics, 146(6), 732-737. https://doi.org/10.1016/j.jpeds.2005.01.055

Taras, H. (2005). Physical activity and student performance at school. Journal of School Health, 75(6). 214-218. https://doi.org/10.1111/j.1746-1561.2005.00026.x

Tassatano, R. M., $\quad$ Barros, M. V. G., $\quad$ Tenorio, M. C. M., Bearra, J., Florindo, A. A., \& Reis, R. S. (2010). Enrollment in physical 
education is associated with health-related behavior among high school student. Journal of School Health, 80, 126-133. https://doi.org/10.1111/j.1746-1561.2009.00476.x

Telford, R. D., Cunningham, R. B., Fitzgerald, R., Olive, L. S., Prosser, L., Jiang, X., \& Telford, R. M. (2012). Physical education, obesity, and academic achievement: A 2-year longitudinal investigation of Australian elementary school children. American Journal of Public Health, 102(2), 368-374. https://doi.org/10.2105/AJPH.2011.300220

Tremblay, M., Inman, J. \& Willms, J. (2000). The relationship between physical activity, selfesteem, and academic achievement in 12-yearold children. Pediatric Exercise Science, 12(3), 312-323. https://doi.org/10.1123/pes.12.3.312

Trudeau, F., \& Shephard, R. J. (2008). Physical education, school physical activity, school sports and academic performance. International Journal of Behavioral Nutrition and Physical Activity, 5, 10. https://doi.org/10.1186/1479-5868-5-10

\section{Information about the author:}

Manci Iris - https://orcid.org/0000-0003-4914-3945; Teacher of the Department of Psychology, Alexander Moisiu University, Durres, Albania. Research interests: education, sports activity, bullying.

\section{Cite this article as:}

Manci, I. (2021). The role of sports activities in students' academic achievements in secondary education. In Yu. B. Melnyk, \& L. M. Georgieva (Eds.), Current Issues of Education and Science. 9th International Conference, CIES-2021, Riga, Latvia - Kharkiv, Ukraine, November 10-13, 2021, Conference proceedings (pp. 7-15). KRPOCH. https://doi.org/10.26697/9786177089147.2021.02

\section{Copyright information:}
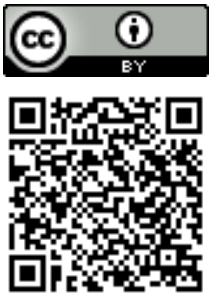

The published paper are licensed under a Creative Commons "Attribution" 4.0 Worldwide

The electronic version of this article is complete. Full or partial reproduction of article is allowed, citing to the source, author(s) and DOI. An electronic copy of the Conference proceedings in open access is available via the KRPOCH Publishing website https://publisher.culturehealth.org 